\title{
Anthraquinone in Indonesian infusion tea: analysis by HPLC-UV and risk assessment
}

\author{
Retno Yusiasih', Mariska M. Pitoi ${ }^{1 *}$, Miranti Ariyani ${ }^{1}$, Tiny A. Koesmawati ${ }^{1,3}$ and Hilman Maulana ${ }^{2}$
}

\begin{abstract}
Background: Detection of anthraquinone in tea samples marketed in Europe is raising a concern due to the possible carcinogenicity of this compound. The European Union has set a very low maximum residue level (MRL) for anthraquinone residue in tea $(0.02 \mathrm{mg} / \mathrm{kg})$. The available method analyses for anthraquinone are mostly by gas chromatography (GC) coupled by mass spectrophotometer (MS) which are relatively more expensive instruments and not always available to moderately equipped laboratories. This study was aimed to analyze anthraquinone in infusion tea of Indonesian commercial tea using liquid chromatography-ultraviolet detector (HPLC-UV) and then assessed the risk associated with consuming infusion tea with anthraquinone residue. The analysis was conducted by low-volume liquid-liquid extraction followed by quantification by HPLC-UV, while the risk assessment was analyzed by calculating the risk quotient $(\mathrm{HQ})$ and carcinogenic risk $(R)$ based on the highest anthraquinone level detected in the sample.

Results: The low-volume liquid-liquid extraction followed by HPLC quantification was able to analyze anthraquinone in infusion tea with linearity of 0.9990 at 8.33 to $83.33 \mu \mathrm{g} / \mathrm{L}$; precision of $2.25 \%$; and recovery of 96.19 to $102.98 \%$. The anthraquinone levels in infusion tea of Indonesian commercial tea varied from not detected to $0.44 \mu \mathrm{g} / \mathrm{L}$. The calculated $\mathrm{HQ}$ is lower than 1 (0.033), implying that consuming Indonesian infusion tea with the detected anthraquinone residue is unlikely to cause non-carcinogenic effect. The $R$ is $2.63 \times 10^{-6}$, but no parametric values have been regulated for anthraquinone; thus, its carcinogenic effect cannot be further assessed.

Conclusion: Low-volume liquid-liquid extraction followed by quantification by HPLC-UV was able to analyze anthraquinone in infusion tea of Indonesian commercial tea samples. Risk assessment showed no prove of adverse effect related to consuming infusion tea as high as the highest concentration detected in infusion tea samples. However, risk associated at higher concentration and/or long-term consumption may not be neglected.
\end{abstract}

Keywords: Anthraquinone, Tea infusion, Green analytical chemistry, Risk assessment

\section{Background}

The occurrence of anthraquinone in tea, which was previously neglected, is recently gaining concerns. It was first detected by laboratories in Europe in 2011 [1] for imported black tea sourcing from China, India, and Sri Lanka [2]. Due to the anthraquinone detection in tea, European Union has set a maximum residue limit of $0.02 \mathrm{mg} / \mathrm{kg}$ for tea Europe [3]. This limit is a two order

\footnotetext{
*Correspondence: mariska.pitoi@gmail.com

${ }^{1}$ Indonesian Institute of Sciences (LIPI)-Research Unit for Clean Technology, Gedung 50 Kampus LIPI Bandung Jl. Sangkuriang, Bandung 40135, Indonesia

Full list of author information is available at the end of the article
}

of magnitude lower compared to other pesticide residues in tea, and, thus, impacts the tea trade in Europe seriously.

Anthraquinone is a possibly carcinogen to humans. Research has shown that this compound caused tumors in kidney, liver, urinary bladder, and thyroid gland of mammalian [4]. International agency for research on cancers (IARC) has classified anthraquinone in group 2B, a possibly carcinogenic to humans, due to the sufficient evidence of carcinogenicity in animal but limited evidence in humans [5]. Chemical and physical properties of anthraquinone are given in Table 1.

Anthraquinone occurrence in the environment is due to several factors. Anthraquinone and its derivatives are 
Table 1 Chemical and physical properties of anthraquinone

$\begin{array}{ll}\text { Chemical structure } & \\ & \end{array}$

All properties are taken from Hazardous Substance Data Bank [6]

naturally found in many plants $[6,7]$ with several serve as natural pigments [6] or pose anti-insecticidal activity [2]. It is known as a bird repellent since 1940s [8] and used in paint, textile, and paper industries [6]. In addition, it was also known as air contaminant [9-12] sourced from diesel automobiles [9] or waste incinerator $[13,14]$.

However, the source of anthraquinone in tea is still uncertain. Despite its application as pesticide had never been registered in China [2], it was detected in exported tea sourced from China, thus, raised questions on how it contaminated the tea. Several sources were suspected contributing to the anthraquinone detection. They were the use of tea bags [15], application of pesticides during plantation [15], and contamination of atmosphere in the plantation [2]. Nevertheless, none is scientifically proven yet.

Analysis of anthraquinone was mostly done as plant extract of anthraquinones [16-18] where the conventional methods such as solid-liquid extraction, maceration, or Soxhlet extraction were performed using high volume of solvents and samples before being analyzed by HPLC-UV. However, as plant extract, anthraquinone analysis was not up to a low value of method detection limit. This is not the case for tea residue analysis where the low detection limit was important and mostly impaired by the complicated matrix of tea. For anthraquinone analysis in tea, the report is limited $[2,19]$ and all the analysis was performed on gas chromatography coupled with tandem mass spectrophotometer (MS/
MS). However, MS, both for single and tandem MS, is relatively costly and usually not available in moderately equipped laboratories [20], and thus, alternative method utilizing relatively cheaper instruments such as HPLCUV is still needed.

Meanwhile, tea is usually consumed as tea infusion. If anthraquinone is present in tea, the channel for anthraquinone to enter the human body is through tea infusion. This study was aimed to analyze anthraquinone in tea infusion of commercial Indonesian tea by utilizing low-volume liquid-liquid extraction followed by quantification using HPLC-UV. The anthraquinone concentration in tea infusion data was then used to assess the risk accompanying drinking tea infusion with anthraquinone residue.

\section{Materials and methods Chemicals and reagents}

Anthraquinone with the purity of $99.4 \%$ was sourced from Chem Service, West Chester, USA. Acetonitrile, $n$-hexane, and acetone were sourced from Merck. Stock solution of anthraquinone was prepared at $39 \mathrm{mg} / \mathrm{L}$ in acetonitrile. Standard solutions were prepared from stock solution by dilution.

\section{Tea samples}

Tea samples are Indonesian commercial tea that was purchased from local supermarkets. The samples were in the package of tea bags or loose leaf. All products were the 
common tea brand produced and sold in Indonesia and were accepted as products indicated in their labels.

\section{Apparatus}

HPLC-UV analysis was performed on an HPLC 7000 series from Hitachi coupled with a UV-visible detector. A $\mu$-BondapakTM $C_{18}(10 \mu \mathrm{m} ; 125 \AA ̊ \AA 3.9 \times 300 \mathrm{~mm})$ from waters was used for separation. The temperature of the column oven was set at $30{ }^{\circ} \mathrm{C}$. The mobile phase was methanol and water with the ratio of 70:30, and was set in an isocratic mode with the flow rate of $0.8 \mathrm{~mL} / \mathrm{min}$ for $15 \mathrm{~min}$. The UV-Vis detector was set at $260 \mathrm{~nm}$. The volume of each injection was $20 \mu \mathrm{L}$.

\section{Analytical procedures and analysis of tea samples}

Performance of the method was validated through spike experiment in which the tea infusion was spiked with anthraquinone. The no-spike experiment was also conducted in parallel with the spike experiment as a control. All the spike and no-spike experiments were extracted according to Fig. 1.

For the real tea sample analysis, tea infusion was prepared by infusing $2 \mathrm{~g}$ of tea samples in $200 \mathrm{~mL}$ of boiling water. The tea infusion was then filtered before being used for the extraction. For the extraction, a $30 \mathrm{~mL}$ of the tea infusion aliquot was used to extract with $3 \mathrm{~mL}$ of $1 \%$ acetone in $n$-hexane. The extraction was performed on a rotary agitator for $15 \mathrm{~min}$ at low speed $(22.5 \mathrm{rpm})$. More details on the extraction procedures are shown in Fig. 1.

\section{Mass spectrometry confirmation}

Confirmation of anthraquinone was done on a Shimadzu GCMS-TQ8030, a gas chromatography coupled with triple quadrupole mass spectrometer (GC-MS/ MS). The system was operated by GCMS solution software. The chromatographic separation was performed on anRxi ${ }^{\circledR}-1 \mathrm{~ms}(30 \mathrm{~m} \times 0.25 \mathrm{~mm} \times 0.25 \mu \mathrm{m})$ from Restek. Each sample was injected $1 \mu \mathrm{L}$ at splitless mode at $270{ }^{\circ} \mathrm{C}$. The oven temperature was programmed at $150{ }^{\circ} \mathrm{C}$ for $2 \mathrm{~min}$ and increased at $5 \mathrm{~mL} / \mathrm{min}$ to $300{ }^{\circ} \mathrm{C}$ and then was held for $2 \mathrm{~min}$. Helium was used as the carrier gas at $2.5 \mathrm{~mL} / \mathrm{min}$. The ion source temperature and interface temperature were $250{ }^{\circ} \mathrm{C}$ and $280{ }^{\circ} \mathrm{C}$, respectively. The solvent cut time was $3.5 \mathrm{~min}$. The mass spectrometer was operated in multiple reaction monitoring (MRM) mode at electron energy of $70 \mathrm{eV}$.

\section{Human risk assessment}

The anthraquinone concentrations in infusion tea samples obtained in this study were then used to assess the carcinogenic and non-carcinogenic risks of anthraquinone as a result of consuming infusion tea from Indonesian market. The hazard quotient (HQ) and carcinogenic risk $(R)$ were estimated to analyze the non-carcinogenic and carcinogenic risks of anthraquinone using Eq. (1) [21], Eq. (2) [22], and Eq. (3) [23, 24]. The HQ was calculated based on the following:

$$
\mathrm{HQ}=\frac{\mathrm{CDI}}{\mathrm{RfD}}
$$

where chronic daily intake (CDI) represented the amount of ingested anthraquinone per kilogram body weight; $\mathrm{RfD}$ was the oral reference dose of the anthraquinone (mg/kg day). Because reference dose (RfD) for anthraquinone was another unknown, the provisional reference dose (P-RfD) for anthraquinone $(0.002 \mathrm{mg} / \mathrm{kg}$ day) proposed by USEPA [25] was used. The CDI was calculated by the following:

$$
\mathrm{CDI}=\frac{C \times \mathrm{IR} \times \mathrm{EF} \times \mathrm{ED}}{\mathrm{BW} \times \mathrm{AT}},
$$

where $C$ represented the measured concentration $(\mathrm{mg} / \mathrm{L})$ of anthraquinone; IR was the infusion tea ingested rate of an Indonesian person that was accounted for $0.38 \mathrm{~kg} /$ year or 190 cups/year $(1 \mathrm{cup}=200 \mathrm{~mL})$ [26]; EF was the exposure frequency (365 days/year); ED was the exposure duration (70 years for adult); BW was the body weight of an adult (70 kg); and AT was the average lifespan $(25,550$ for adult). For the carcinogenic risk $(R)$, the formulation below was used by the following:

$$
R=\mathrm{CDI} \times \mathrm{SF} \times \mathrm{ADAF},
$$

where SF was the cancer slope factor ( $\mathrm{mg} / \mathrm{kg}$ day). Similar to RfD, because of cancer slope factor for anthraquinone which was another unknown, the provisional oral slope factor (P-OSF) for anthraquinone $(0.04 \mathrm{mg} / \mathrm{kg}$ day) proposed by USEPA [25] was used. ADAF was the agedependent adjustment factor ( 1 for above 16 years old).

\section{Result and discussion Chromatographic performance}

The absorption spectra of anthraquinone were studied at wavelength of 254-270 nm (Fig. 2) with methanol and water as the mobile phase. The compound showed the maximum absorbance at $260 \mathrm{~nm}$, so, for the next experiment, the HPLC analysis was performed at $260 \mathrm{~nm}$.

Figure 3 shows the chromatograms of standard solution of anthraquinone, and tea sample extract with and without anthraquinone. It can be seen that anthraquinone was eluted at around $10.24 \mathrm{~min}$. Meanwhile, for tea infusion matrix, the interference peaks came early and did not interfere with the target compound anthraquinone. This benefited the extraction, since no 


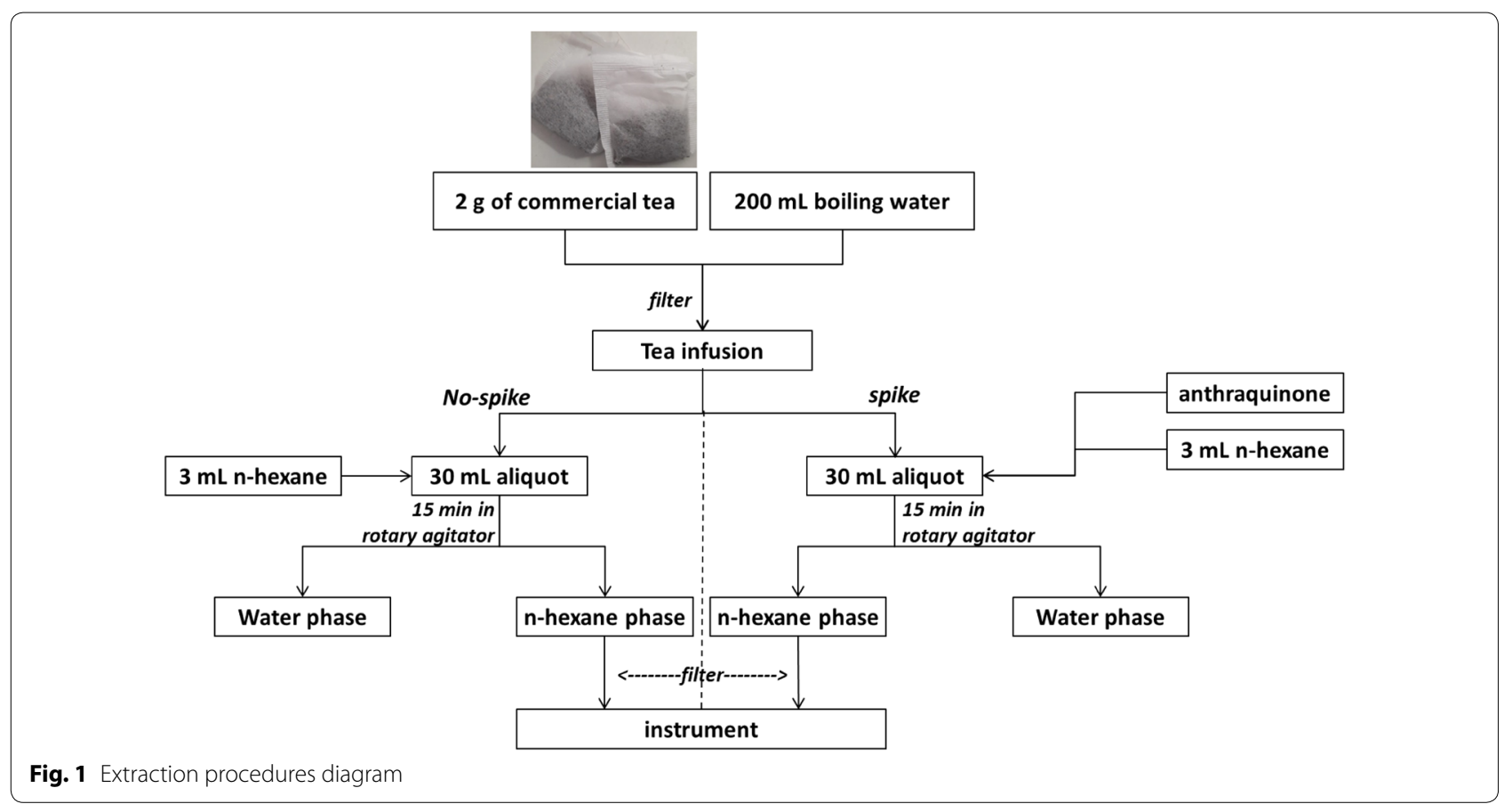

further clean-up is needed. For residue analysis in tea samples that performed on MS or MS/MS detectors, this usually was not the case. Tea was known of its complicated matrix, and clean up using primary secondary amine (PSA), florisil, and graphitized carbon black (GCB) are usually applied during sample preparation/extraction to remove interferences [2, 19, 27-29]. For anthraquinone analysis in tea, PSA combined with GCB [19] and florisil [2] were normally used to clean up interferences. However, in our case, since the interferences in tea that usually observed during GC-MS quantification were not detected due to their inactivity to the UV detector, the clean-up step was not required and, thus, simplified the extraction method. Without clean-up step that normally is applied for tea-based analysis, the time for the extraction is shortened and budget for clean-up chemicals is minimalized.

Calibration curve for standard solutions of anthraquinone was constructed at 13 concentration levels from 6.24 to $156 \mu \mathrm{g} / \mathrm{L}$ and then plotted the peak area against each concentration. Concentration of $6.24 \mu \mathrm{g} / \mathrm{L}$ was the lowest concentration that can be detected, and, therefore, was appointed as the instrument detection limit (IDL). The detector response for all the standard solutions was fitted to linear regression and gave a coefficient correlation of 0.9999 (Table 2), indicating good linearity of the standard solutions.

The precision of chromatographic system was evaluated by analyzing anthraquinone standard solution at

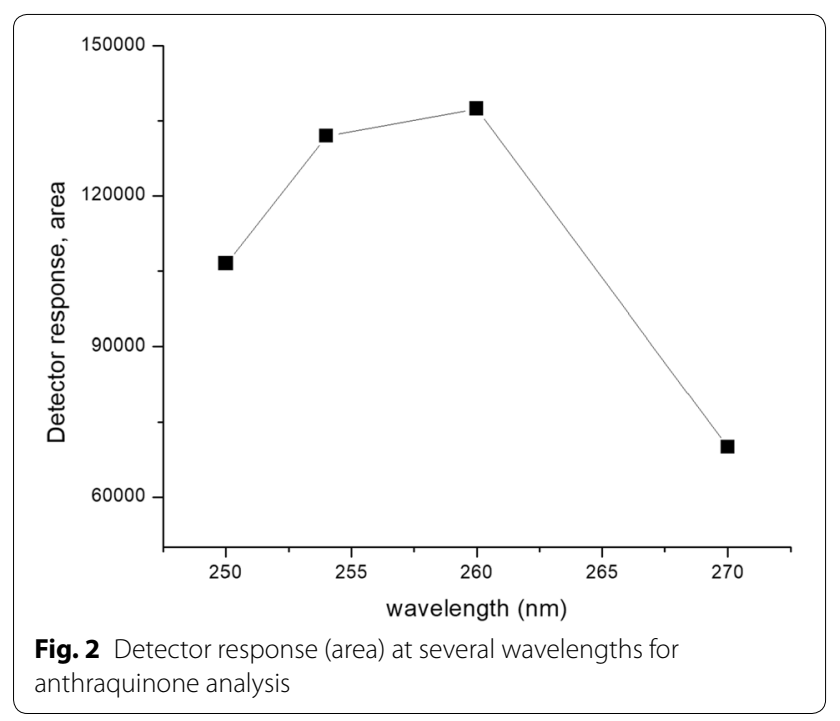

$6.24 \mu \mathrm{g} / \mathrm{L}$ by seven independent injections. The percent relative standard deviation (RSD) was acceptable with a value below of the $2 / 3$ Horwitz coefficient of variation $\left(\mathrm{CV}_{\text {Horwitz }}\right)$ value, as shown in Table 2.

\section{Analytical performance}

The linearity of the method for the spike experiment was evaluated at one order of magnitude concentration, ranging from 8.33 to $83.33 \mu \mathrm{g} / \mathrm{L}$. Linear relationship between the corresponding peak area and the concentration of 


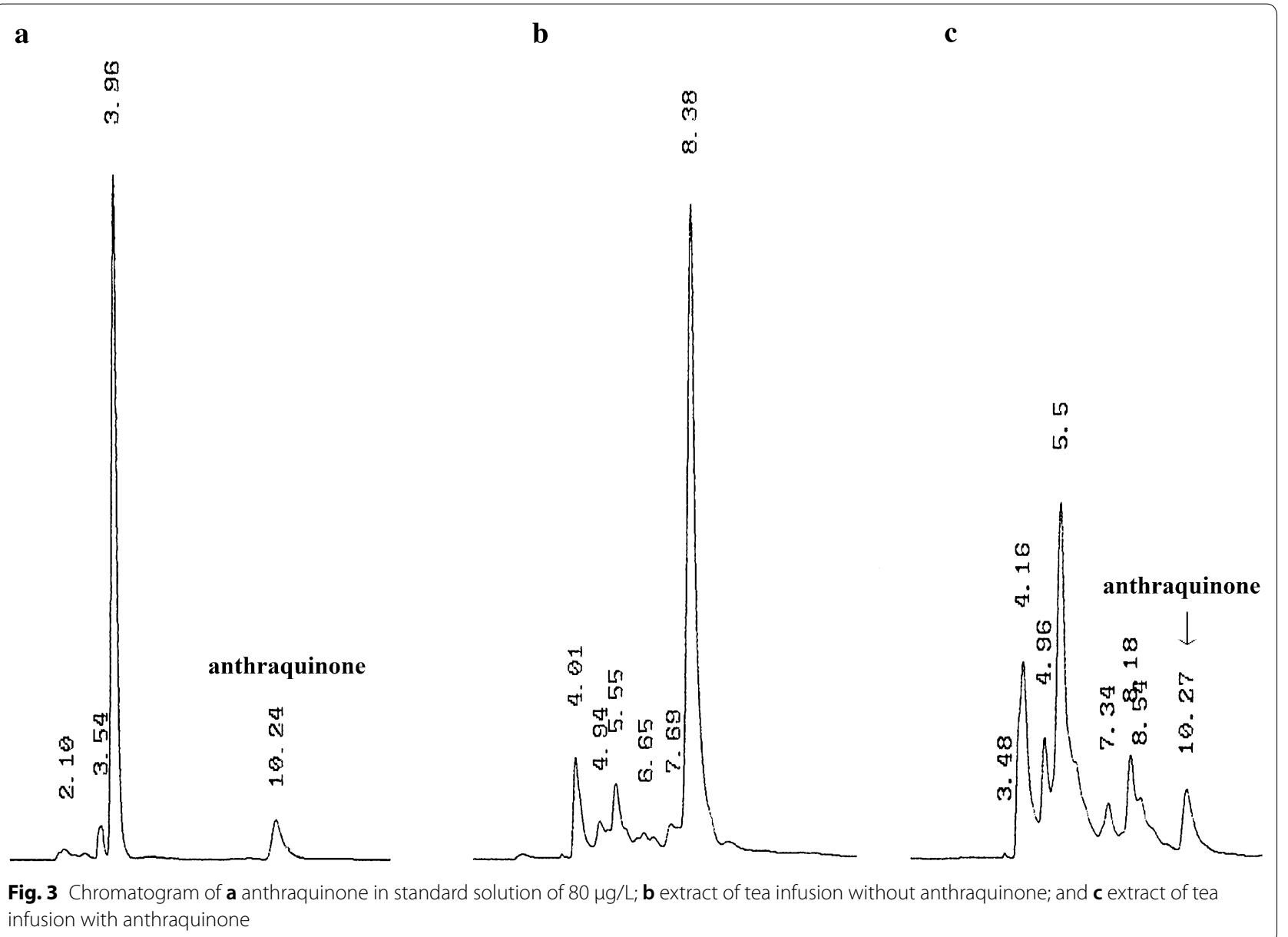

analytes was observed, showed by a close to $1 r$ value accounted for 0.9990 (Fig. 4).

The precision of the method was assessed by applying the extraction procedures to the tea infusion with anthraquinone and the extraction was done in seven replicates for the same tea infusion. As shown in Table 3, the precision of the method was acceptable with a lower \% RSD (2.25\%) compared to the two-thirds of calculated $\mathrm{CV}_{\text {Horwitz }}$ (21.96\%). Similarly, the \% RSD also lower compared to AOAC guideline [30]. This implies that the extraction method is precise.

The accuracy of the analytical method was evaluated by the recovery data. The tea infusion was spiked with anthraquinone at concentration levels of 8.33 to $83.33 \mu \mathrm{g} / \mathrm{L}$ and then was extracted by the method. Prior to analyte fortification, the background level of [2] tea infusion was also determined for the recovery calculation. The recoveries obtained in this study were in between 96.19 and $102.98 \%$ with an average of $99.52 \%$. These values are in the acceptable range as in the AOAC guidelines (80110\%) [30] and European Union guideline (70-120\%) [31].
Table 2 Evaluation of HPLC-UV performance

\begin{tabular}{ll}
\hline Parameters & Anthraquinone \\
\hline Linear regression equation & $y=117.26 \times+95.449$ \\
Coefficient correlation $(r)$ & 0.9999 \\
Linear range & $6.24-156 \mu \mathrm{g} / \mathrm{L}$ \\
Instrument detection limit (IDL) & $6.24 \mu \mathrm{g} / \mathrm{L}$ \\
Relative standard deviation (RSD) at $6.24 \mu \mathrm{g} / \mathrm{L}$ & $15.68 \%$ \\
$\quad(n=7)$ & \\
CV & $34.15 \%$ \\
\hline
\end{tabular}

This method was able to quantify anthraquinone in infusion tea as low as $8.33 \mu \mathrm{g} / \mathrm{L}$. If we assume that all anthraquinone in tea sample $(2 \mathrm{~g})$ is transferred to the infusion tea $(200 \mathrm{~mL})$, then the LOQ of this method is equivalent to $0.833 \mathrm{mg} / \mathrm{kg}$ which is around 42 -fold of the MRL regulated by European Union [3]. However, the previous report showed that anthraquinone has low solubility with only 1.6 to $13.7 \%$ brew to the infusion tea [2], and thus, the equivalent LOQ of this method will be ranging from 0.013 to $0.114 \mathrm{mg} / \mathrm{kg}$. It can be seen that the lowest 


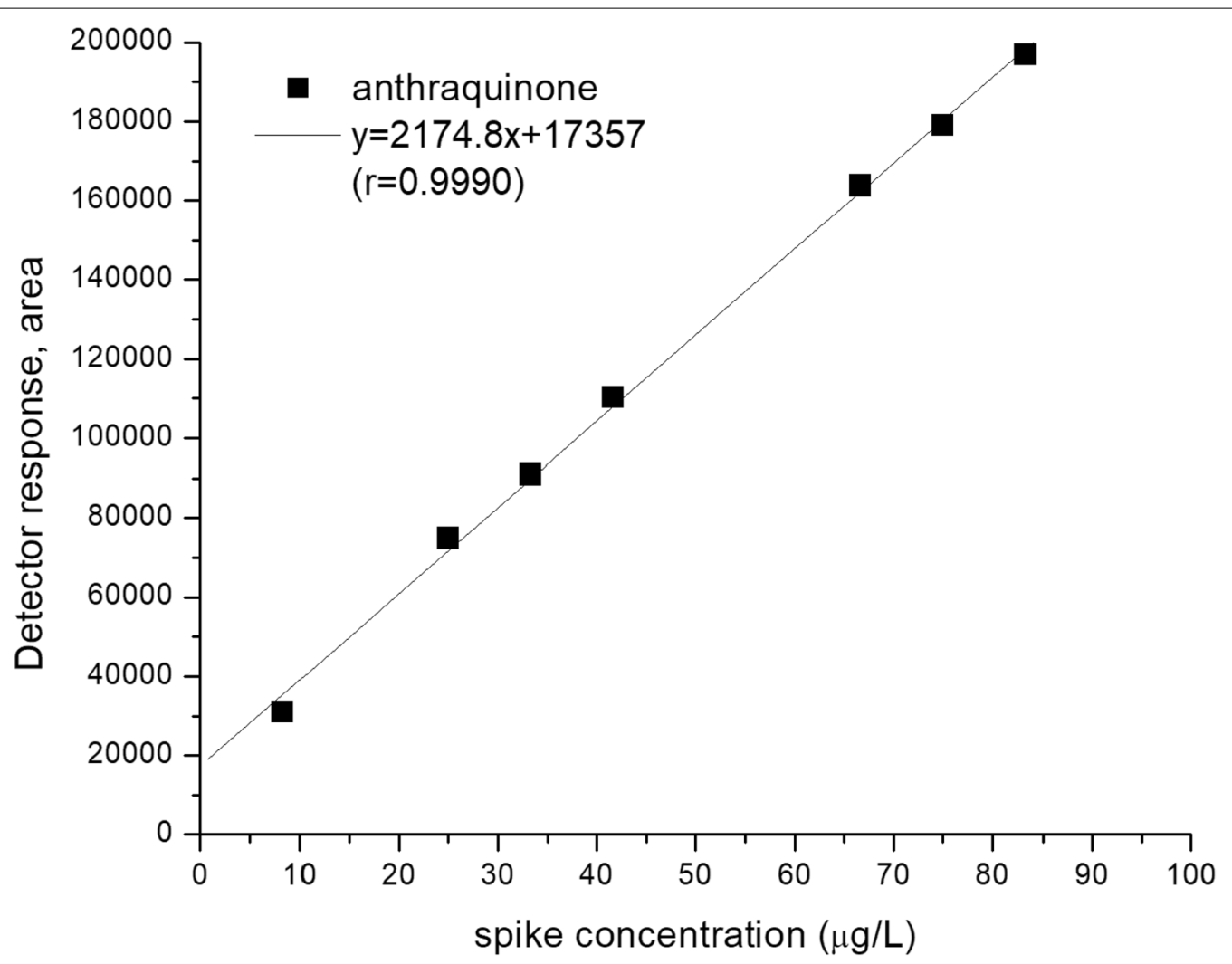

Fig. 4 Linearity of the method at $8.33-83.33 \mu \mathrm{g} / \mathrm{L}$

value of the equivalent LOQ $(0.013 \mathrm{mg} / \mathrm{kg})$ is lower than the MRL, while the highest value is higher than the MRL. The transfer behavior of anthraquinone from dried tea to infusion tea is likely to be temperature- and concentration-dependent [2], and thus, the equivalent LOQ values obtained in our study are likely to be affected by temperature when preparing the infusion tea and the anthraquinone concentration in the dried tea used to prepare the infusion tea. Therefore, this method is not suggested to be used to determine the anthraquinone level in tea (dried) to meet the requirement set by the European Union and can only be used to determine the anthraquinone level in infusion tea as low as $8.33 \mu \mathrm{g} / \mathrm{L}$. In the case of anthraquinone determination in dried tea (as required by European Union), method which utilizes gas chromatography with tandem mass spectrophotometer (GCMS/MS) is still more sensitive and can achieve LOQ as low as $0.01 \mathrm{mg} / \mathrm{kg}$ [2] which is lower than the MRL. Similarly, utilization of GC-MS/MS for anthraquinone analysis in infusion tea can achieve a lower LOQ $(0.4 \mu \mathrm{g} / \mathrm{L})$ [2] compared to our method. However, both applied cleanup step which was not use in our method.

Anthraquinone was confirmed by GC-MS/MS at conditions explained in the methods. The transition of
Table 3 Evaluation of the method performance (precision, recovery, and uncertainty measurement)

\begin{tabular}{ll}
\hline Parameters & Results \\
\hline Spiked concentration & $8.33 \mu \mathrm{g} / \mathrm{L}$ \\
Extracted concentration (average) & $8.29 \mu \mathrm{g} / \mathrm{L}$ \\
Percent recovery & $96.19-102.98 \%$ \\
& (average \\
$N$ & $99.52 \%)$ \\
RSD, \% & 7 \\
$\mathrm{CV}_{\text {Horwitz }}$ & 2.25 \\
2/3 CV Horwitz & 32.94 \\
Uncertainty & 21.96 \\
\hline
\end{tabular}

$\mathrm{m} / z 180$ to $\mathrm{m} / z 152$ was used as quantifier while transition of $\mathrm{m} / z 208$ to $\mathrm{m} / z 152$ was used for anthraquinone confirmation. These transitions are corresponding to the removal of one molecule of CO (180-152) or two molecules of CO (208-152) as proposed in the previous research of anthraquinone analysis by GC-MS/MS [2]. 


\section{Real sample analysis and risk assessment}

The performance of HPLC-UV and analytical method described above was applied for anthraquinone analysis in tea infusion for the real samples of tea bags and loose leaf produced and marketed in Indonesia. Tea bags and loose leaf tea were chosen, since they are the most consumed tea products in Indonesia [32]. Moreover, since tea bags and loose leaf tea were consumed as tea infusion, thus, anthraquinone, if present in tea, will be exposed to humans through tea infusion. Therefore, tea infusion was chosen as the matrix for the analysis.

For the analysis, tea samples were extracted according to the method (Fig. 1). The extraction was performed in duplicate for each sample and the results are summarized in Table 4. As shown in the table, there is a high degree of variability for the anthraquinone content in commercial tea marketed in Indonesia, as low as not detected to $44 \mu \mathrm{g} / \mathrm{L}$. To our knowledge, there was no report on anthraquinone concentration on tea infusion for real samples. Report on anthraquinone concentration on tea infusion was limited to anthraquinone fortification on tea samples (anthraquinone has been applied in field trial) to see the infusion behavior of anthraquinone from tea to tea brew [2]. Since anthraquinone pose a low solubility in water $\left(1.353 \mathrm{mg} / \mathrm{L}\right.$ at $\left.25^{\circ} \mathrm{C}\right)$ [6] with only $1.6-13.7 \%$ of it brews into tea infusion [2], thus, it can be predicted that anthraquinone concentrations in tea bag or loose tea samples are higher than what are detected in tea infusion as investigated in this study.

However, as mentioned earlier, since tea bags and loose leaf tea are consumed as tea infusion, the risk of anthraquinone in tea bags and loose tea that are not leached into tea infusion (or anthraquinone in spent tea) is not important and can be neglected. Nevertheless, anthraquinone detection on tea infusion is a concern due to its carcinogenicity, although daily permitted intake of anthraquinone for human has not yet been determined or evaluated.

Assuming that anthraquinone daily intake is only from tea infusion, the risk for consuming infusion tea with anthraquinone residue with concentration level as detected in this study is predicted. The non-carcinogenic risk was estimated based on the hazard quotient or HQ (Eq. 1) and the result is given in Table 5. If the Indonesian tea consumption per capita is $0.38 \mathrm{~kg} /$ years [26] and the intake of anthraquinone is the highest anthraquinone detected in this study $(44 \mu \mathrm{g} / \mathrm{L})$, then HQ for an adult with a $70-\mathrm{kg}$ body weight is 0.033 . This value $(\mathrm{HQ}<1)$ implies that there is non-carcinogenic effect resulting from consuming Indonesian infusion tea.

The carcinogenic risk $(R)$ value was calculated using Eqs. (2 and 3). The calculated $R$ value is $2.63 \times 10^{-6}$ (Table 5). Usually, the $R$ value is compared to parametric

\section{Table 4 Anthraquinone and recovery in Indonesian commercial tea $(n=2)$}

\begin{tabular}{llc}
\hline Real samples & Anthraquinone $(\boldsymbol{\mu g} / \mathbf{L})$ & Recovery (\%) \\
\hline SP-01 & ND & 95.78 \\
SP-02 & ND & 101.73 \\
SP-03 & ND & 97.92 \\
SP-04 & 8.17 & 105.07 \\
SP-05 & ND & 88.87 \\
SP-06 & 0.57 & 106.75 \\
SP-07 & 16.24 & 86.74 \\
SP-08 & 7.06 & 97.53 \\
SP-09 & 20.41 & 94.14 \\
SP-10 & ND & 82.35 \\
SP-11 & 22.80 & 117.53 \\
SP-12 & ND & 105.39 \\
SP-13 & 6.32 & 99.54 \\
SP-14 & 6.12 & 89.52 \\
SP-15 & 26.26 & 77.76 \\
SP-16 & 44.23 & 84.18 \\
SP-17 & 32.82 & 112.96 \\
\hline ND & &
\end{tabular}

ND non detected

value recommended by regulators. However, since anthraquinone carcinogenic study is limited and parametric value recommended by regulators such as EU, USEPA, or WHO is absent, that obtained $R$ value is meaningless and cannot be used to assess the carcinogenic risk of anthraquinone.

Further assessment was then conducted based on the previous reports on anthraquinone carcinogenicity for mammals as comparison. Again, assuming that anthraquinone daily intake is only from tea infusion, for an adult with $70-\mathrm{kg}$ body weight who drinks two cups of tea infusion $(200 \mathrm{~mL})$ daily with $44 \mu \mathrm{g} / \mathrm{L}$ of anthraquinone, the anthraquinone daily intake will be a total of $0.0176 \mathrm{mg}$ or $2.5 \times 10^{-4} \mathrm{mg}$ anthraquinone per $\mathrm{kg}$ of body weight. The previous research showed that daily intake of $125.3 \mathrm{mg} / \mathrm{kg}$ day (human equivalent dose) of anthraquinone in male mice for 2 years, which is 6 order of magnitude greater than the simulated concentration in this study, has bring negative effect such as increasing the incident of tumors (hepatocellular adenoma, carcinoma, and hepatoblastoma) up to $98 \%$ [25]. Moreover, daily intake of $50 \mathrm{mg} / \mathrm{kg}$ body weight of female rats for 105 weeks resulted in incidence of papilloma that was significantly different from the control [6]. Unfortunately, there was no information on lower concentration of daily intake of anthraquinone in the last report [6]. In addition, excretion of anthraquinone was quick in animal, with almost 96\% was excreted in urine and feces within 2 days [6]. 
Table 5 Human risk assessment

\begin{tabular}{|c|c|}
\hline Measured concentration & $44.23 \mu \mathrm{g} / \mathrm{L}$ \\
\hline Infusion tea ingested rate of Indonesian (IR) & $\begin{array}{l}0.38 \mathrm{~kg} / \text { year (or } 190 \text { cups/ } \\
\text { year or } 0.38 \mathrm{~L} / \text { year) }\end{array}$ \\
\hline Exposure frequency (EF) & 365 days/year \\
\hline Exposure duration (ED) & 70 years (adult) \\
\hline Body weight (BW) & $70 \mathrm{~kg}$ \\
\hline Average lifespan & 25,550 day (adult) \\
\hline Chronic daily intake (CDI) & $6.57824 \times 10^{-5} \mathrm{mg} / \mathrm{kg}$ day \\
\hline Oral reference dose & $0.002 \mathrm{mg} / \mathrm{kg} \mathrm{day}^{\mathrm{a}}$ \\
\hline HAZARD quotient (HQ) & 0.033 \\
\hline Provisional oral slope factor (P-OSF) & 0.04 mg/kg day ${ }^{a}$ \\
\hline Age-dependent adjustment fact (ADAF) & 1 (> 16 years old) \\
\hline Carcinogenic risk $(R)$ & $2.63 \times 10^{-6}$ \\
\hline
\end{tabular}

a USEPA [25]

From the above-mentioned reports, there was no proof for the adverse effects of anthraquinone if it was taken as tea infusion contaminant at the level of concentration detected in this study for short period of exposure. However, for daily intake at higher concentration and or at prolonged exposure of anthraquinone, the adverse effect may not be neglected. Nevertheless, this prediction is needed to be scientifically proven.

The accuracy of the method in term of recovery was also evaluated for all the samples. Anthraquinone was spiked to all samples and the area was subtracted from the no-spike experiment. It was found that the recovery for all samples was in the range suggested by European Union [31] for pesticide residue analysis, and 15 of 17 samples were in the range suggested by AOAC [30] (Table 4).

\section{Conclusion}

A simple extraction procedure including low-volume liquid-liquid extraction without a clean-up step, followed by HPLC-UV quantification, was able to determination anthraquinone in infusion tea of commercial Indonesian tea and no adverse effect resulting from consuming Indonesian infusion tea observed in this study.

\footnotetext{
Abbreviations

ADAF: age-dependent adjustment factor; AT: average lifespan; BW: body weight; C: concentration; CDI: chronic daily intake; $\mathrm{CV}_{\text {Horwitz }}$ : Horwitz coefficient of variation; ED: exposure duration; EF: exposure frequency; GC: gas chromatography; GCB: graphitized carbon black; HPLC: high-performance liquid chromatography; HQ: hazard quotient; IDL: instrument detection limit; IR: ingested rate; MRL: maximum residue level; MS: mass spectrophotometer; MS/MS: tandem mass spectrophotometer; P-OSF: provisional oral slope factor; P-RfD: provisional reference dose; PSA: primary secondary amine; $R$ : carcinogenic risk; RfD: oral reference dose; RSD: relative standard deviation; SF: slope factor; UV: ultra violet; UV-Vis: ultraviolet-visible.
}

\section{Acknowledgements}

We would like to express our thank you to Mr. Harmoko for helping with stock solution preparation and GC-MS/MS analysis and Ms Delis for the sample preparation.

\section{Authors' contributions}

RY planned the experimental design, conducted the research including validate the method for the analysis, and interpreted the data; MMP (corresponding author) prepared the manuscript; MA prepared the risk assessment and critically reviewed the manuscript. TAK provided the guidance for method validation; HM provided the guidance for tea and helped with the tea samples. All authors read and approved the final manuscript.

\section{Funding}

This research was financially supported by INSINAS Research Grant Program 2018-2019 (contract no. 027/RPL/INSINAS-2/VII/2018 and 047/P/RPL-LIPI/ INSINAS-1/II/2019) from the Ministry of Research, Technology and Higher Education, Indonesia.

\section{Availability of data and materials}

Additional data may be available on request to the authors; please contact the corresponding author.

\section{Ethics approval and consent to participate}

The authors declare that this study does not involve human subjects, human material, and human data.This manuscript is an original article and has not published in other journals. The authors agree to comply with the copyright rule.

\section{Consent for publication}

The authors agreed to the publication of the manuscript in this journal. The authors grant the accessibility of the scientific article in agreement of the springer policy.

\section{Competing interests}

The authors declare that they have no competing interests.

\section{Author details}

${ }_{1}^{1}$ Indonesian Institute of Sciences (LIPI)-Research Unit for Clean Technology, Gedung 50 Kampus LIPI Bandung J. Sangkuriang, Bandung 40135, Indonesia. ${ }^{2}$ Research Institute for Tea and Cinchona, Gambung, KotakPos 1013, Bandung 40010, Indonesia. ${ }^{3}$ Bakti Asih Higher Education for Analyst, Jl. Padasuka Atas, Bandung 40192, Indonesia.

Received: 20 March 2019 Accepted: 27 May 2019

Published online: 04 September 2019

\section{References}

1. BNN. Public statement on the application of the BNN orientation value for biphenyl and anthraquinone detected in organic herbs, spices, herbal teas and tea (Camellia sinensis). Berlin: Bundesverband Naturkost Naturwaren; 2015.

2. Wang X, Zhou L, Luo F, Zhang X, Sun H, Yang M, Lou Z, Chen Z. 9, 10-Anthraquinone deposit in tea plantation might be one of the reasons for contamination in tea. Food Chem. 2018;244:254-9. https://doi. org/10.1016/j.foodchem.2017.09.123.

3. EU. COMMISSION REGULATION (EU) No 1146/2014. Official Journal of the European Union; 2014.

4. NTP. NTP Toxicology and Carcinogenesis Studies of ANTHRAQUINONE (CAS NO. 84-65-1) Feed Studies in F344/N Rats and B6C3F1 Mice. National Toxicology Program technical report series. 2005;494:1.

5. IARC. IARC Monographs on the evaluation of carcinogenic risks to humans. Volume 101. 2013; 2013.

6. Hazardous Substance Data Bank. Anthraquinone. U.S. National Library of Medicine. 2006.

7. Thomson R. Naturally occurring quinones. Amsterdam: Elsevier; 2012

8. DeLiberto ST, Werner SJ. Review of anthraquinone applications for pest management and agricultural crop protection. Pest Manag Sci. 2016;72(10):1813-25. https://doi.org/10.1002/ps.4330. 
9. Yu M-L, Hites RA. Identification of organic compounds on diesel engine soot. Anal Chem. 1981;53(7):951-4. https://doi.org/10.1021/ac00230a005.

10. Galceran MT, Moyano E. Determination of oxygenated and nitro-substituted polycyclic aromatic hydrocarbons by HPLC and electrochemical detection. Talanta. 1993;40(5):615-21. https://doi.org/10.1016/00399140(93)80266-T.

11. Oda J, Maeda I, Mori T, Yasuhara A, Saito Y. The relative proportions of polycyclic aromatic hydrocarbons and oxygenated derivatives in accumulated organic particulates as affected by air pollution sources. Environ Technol. 1998;19(10):961-76. https://doi.org/10.1080/095933319086167 55.

12. Sklorz M, Briedé J-J, Schnelle-Kreis J, Liu Y, Cyrys J, de Kok TM, et al. Concentration of oxygenated polycyclic aromatic hydrocarbons and oxygen free radical formation from urban particulate matter. J Toxicol Environ Health A. 2007;70(21):1866-9. https://doi.org/10.1080/152873907014576 54.

13. James RH, Adams RE, Finkel JM, Miller HC, Johnson LD. Evaluation of analytical methods for the determination of $\mathrm{POHC}$ in combustion products. J Air Pollut Control Assoc. 1985;35(9):959-69. https://doi. org/10.1080/00022470.1985.10465986.

14. Akimoto Y, Aoki T, Nito S, Inouye Y. Oxygenated polycyclic aromatic hydrocarbons from MSW incinerator fly ash. Chemosphere. 1997;34(2):263-73. https://doi.org/10.1016/S0045-6535(96)00376-1.

15. EURL. EURL-PROFICIENCY TEST-T02, 2014 pesticide residues in tea homogenate 2014

16. Barrera Vázquez MF, Comini LR, Martini RE, Núñez Montoya SC, Bottini S, Cabrera JL. Comparisons between conventional, ultrasound-assisted and microwave-assisted methods for extraction of anthraquinones from Heterophyllaea pustulata Hook f. (Rubiaceae). Ultrason Sonochem. 2014;21(2):478-84. https://doi.org/10.1016/j.ultsonch.2013.08.023.

17. Duval J, Pecher V, Poujol M, Lesellier E. Research advances for the extraction, analysis and uses of anthraquinones: a review. Ind Crops Prod. 2016;94:812-33. https://doi.org/10.1016/j.indcrop.2016.09.056.

18. Deng S, West BJ, Jensen CJ, Basar S, Westendorf J. Development and validation of an RP-HPLC method for the analysis of anthraquinones in noni fruits and leaves. Food Chem. 2009;1 16(2):505-8. https://doi. org/10.1016/j.foodchem.2009.02.070.

19. Hayward DG, Wong JW, Park HY. Determinations for pesticides on Black Green, Oolong, and White Teas by gas chromatography triple-quadrupole mass spectrometry. J Agric Food Chem. 2015;63(37):8116-24. https://doi. org/10.1021/acs.jafc.5b02860.

20. Rahman MM, Abd El-Aty A, Kim SW, Shin SC, Shin HC, Shim JH. Quick, easy, cheap, effective, rugged, and safe sample preparation approach for pesticide residue analysis using traditional detectors in chromatography: a review. J Sep Sci. 2017;40(1):203-12. https://doi.org/10.1002/jssc.20160 0889

21. Shi W, Zhang F, Zhang X, Su G, Wei S, Liu H, et al. Identification of trace organic pollutants in freshwater sources in Eastern China and estimation of their associated human health risks. Ecotoxicology. 2011;20(5):1099106. https://doi.org/10.1007/s10646-011-0671-8.
22. Hu Y, Qi S, Zhang J, Tan L, Zhang J, Wang Y, et al. Assessment of organochlorine pesticides contamination in underground rivers in Chongging, Southwest China. J Geochem Explor. 2011;111(1-2):47-55. https://doi. org/10.1016/j.gexplo.2011.07.006.

23. USEPA. Supplementary guidance for conducting health risk assessment of chemical mixtures. Risk Assessment Forum Technical Panel. Office EPA/360/R-00/002:: US Environmental Protection Agency. 2000.

24. Kim HH, Lim YW, Yang JY, Shin DC, Ham HS, Choi BS, Lee JY. Health risk assessment of exposure to chlorpyrifos and dichlorvos in children at childcare facilities. Sci Total Environ. 2013;444:441-50. https://doi. org/10.1016/j.scitotenv.2012.11.102.

25. USEPA. provisional peer-reviewed toxicity values for 9,10-Anthraquinone (CASRN 84-65-1), Superfund Health Risk Technical Support Center, National Center for Environmental Assessment Office of Research and Development. U.S. Environmental Protection Agency. 2011.

26. PPID. Outlook Teh Komoditas Pertanian Subsektor Perkebunan: Pusat Data dan Sistem Informasi Pertanian, Sekretariat Jenderal Kementerian Pertanian. 2016.

27. Fan CL, Chang QY, Pang GF, Li ZY, Kang J, Pan GQ, Zheng SZ, Wang WW, Yao CC, Ji XX. High-throughput analytical techniques for determination of residues of 653 multiclass pesticides and chemical pollutants in tea-part V: a comparative study of the influence of tea hydration on the efficiency of pesticide multiresidue determination using three sample preparation methods and GC/MS/MS. J AOAC Int. 2015;98(1):149-59. https://doi.org/10.5740/jaoacint.13-279.

28. Wang F, Li S, Feng H, Yang Y, Xiao B, Chen D. An enhanced sensitivity and cleanup strategy for the nontargeted screening and targeted determination of pesticides in tea using modified dispersive solid-phase extraction and cold-induced acetonitrile aqueous two-phase systems coupled with liquid chromatography-high resolution mass spectrometry. Food Chem. 2019:275:530-8. https://doi.org/10.1016/j.foodchem.2018.09.142.

29. Wang J, Cheung W, Leung D. Determination of pesticide residue transfer rates (percent) from dried tea leaves to brewed tea. J Agric Food Chem. 2014;62(4):966-83. https://doi.org/10.1021/jf404123h.

30. AOAC. Appendix F: guidelines for Standard METHOD performance requirements, Official Methods of Analysis of AOAC 2016.

31. EC. Guidance document on pesticide residue analytical methods 2010. https://ec.europa.eu/food/sites/food/files/plant/docs/pesticides_ppp_ app-proc_guide_res_post-reg-cont-monitor.pdf.

32. BPS-RI. Pengeluaran untuk Konsumsi Penduduk Indonesia, Maret 2018: Badan Pusat Statistik Republik Indonesia. 2018.

\section{Publisher's Note}

Springer Nature remains neutral with regard to jurisdictional claims in published maps and institutional affiliations.

\section{Submit your manuscript to a SpringerOpen ${ }^{\circ}$ journal and benefit from:}

- Convenient online submission

- Rigorous peer review

- Open access: articles freely available online

- High visibility within the field

- Retaining the copyright to your article

Submit your next manuscript at $\boldsymbol{\nabla}$ springeropen.com 